\title{
Sublingual heterotopic large cyst in a newborn: anesthetic management
}

\author{
Hanife Karakaya Kabukcu, MD • Asli Bostanci, MD • Murat Turhan, MD • \\ Tulin Aydogdu Titiz, MD
}

Received: 26 April 2017/Revised: 5 May 2017/Accepted: 10 May 2017/Published online: 15 May 2017

(C) Canadian Anesthesiologists' Society 2017

A one-month-old 3,950-g male infant was hospitalized with a sublingual cystic lesion that caused feeding difficulty and respiratory distress. The cyst was first diagnosed in the fourth month of pregnancy during a routine prenatal ultrasound examination. Shortly after delivery, the cyst was reduced in size by needle aspiration. It rapidly re-grew, however, and on return to hospital, a cystic lesion $(4 \times 4 \mathrm{~cm})$ on the ventral surface of the infant's tongue extended outside the oral cavity (Figure, panel $A$ ). In the accompanying magnetic resonance
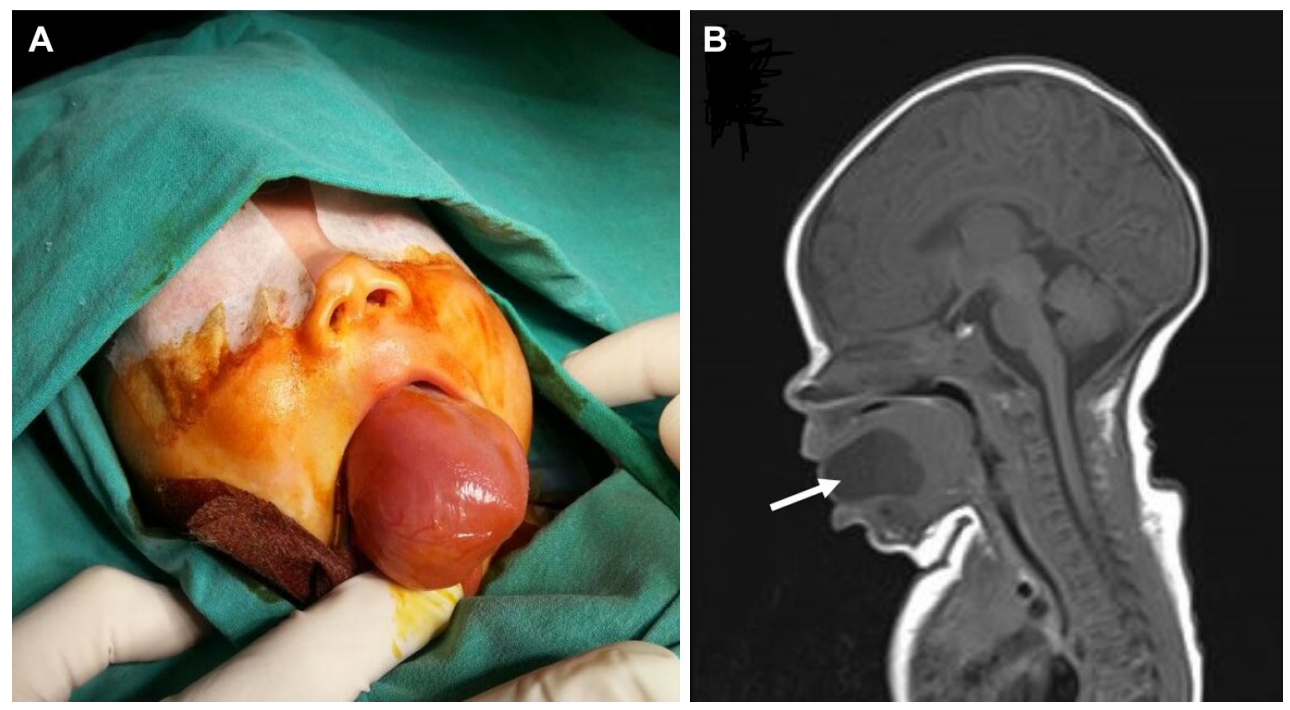

Figure A) External appearance of the mass protruding from the mouth of this one-month-old infant. B) Lateral magnetic resonance image also shows the large sublingual cyst (arrow) and a patent upper airway

H. K. Kabukcu, MD $(\bowtie) \cdot$ T. A. Titiz, MD

Department of Anesthesiology and Reanimation, Akdeniz

University Medical Faculty, Antalya, Turkey

e-mail: hanifekabukcu@akdeniz.edu.tr

A. Bostanci, MD - M. Turhan, MD

Department of Ear Nose and Throat, Akdeniz University

Medical Faculty, Antalya, Turkey 
imaging study, the cyst was seen to be limited to the floor of the mouth without impingement on the trachea (Figure, panel B).

The patient was taken to the operating room for surgical resection of the sublingual cyst. Anesthetic masks of various sizes and shapes, a laryngeal mask supraglottic airway, and other oropharyngeal airways were prepared before induction of anesthesia. In addition, a surgical team was immediately available should tracheostomy be deemed necessary. Following pre-oxygenation with $100 \% \mathrm{O}_{2}$, we proceeded with an inhalational anesthetic induction with sevoflurane and then administered succinylcholine $5 \mathrm{mg}$ after establishing positive pressure bag and mask ventilation. We initially attempted laryngoscopy with a Miller blade, but could not visualize the glottis due to impingement of the distorted tongue. Consequently, we reattempted laryngoscopy with a size 0 Macintosh blade. The blade was advanced to the base of the infant's tongue using a right molar approach, and with an assistant pulling the tongue in the midline, we were able to position the tip of the blade in the midline. We next applied gentle cricoid pressure. This allowed us to visualize the vocal cords and to advance an uncuffed $3.5-\mathrm{mm}$ endotracheal tube with stylet into the patient's trachea under direct vision. The sublingual cyst was successfully excised after careful dissection through the mouth floor and surrounding tissues. Laryngoscopy using a molar approach and a Macintosh blade facilitated successful intubation.

Conflict of interest None declared.

Editorial responsibility This submission was handled by Dr. Hilary P. Grocott, Editor-in-Chief, Canadian Journal of Anesthesia.

Funding There was no financial support or funding. 